
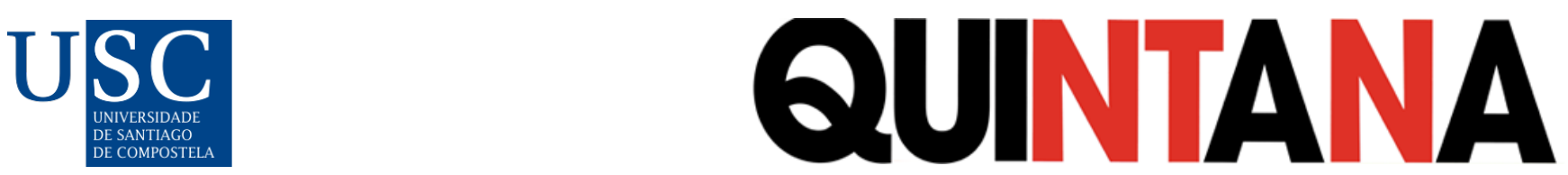

Quintana: revista do Departamento de Historia da Arte, (20), 2021. ISSN-e: 2340-0005

https://doi.org/10.15304/quintana.20.8056

Escritos sobre ...

\title{
CARTA-QUENTA, O RAZÓN EN SUMA DE LAS FESTIVAS GOZOSAS DEMOSTRACIONES CON QUE LA CIUDAD DE SANTIAGO DE GALICIA CELEBRÓ LA SOLEMNE ACLAMACIÓN DE NUESTRO REY CARLOS III
}

Diego Antonio Cernadas de Castro

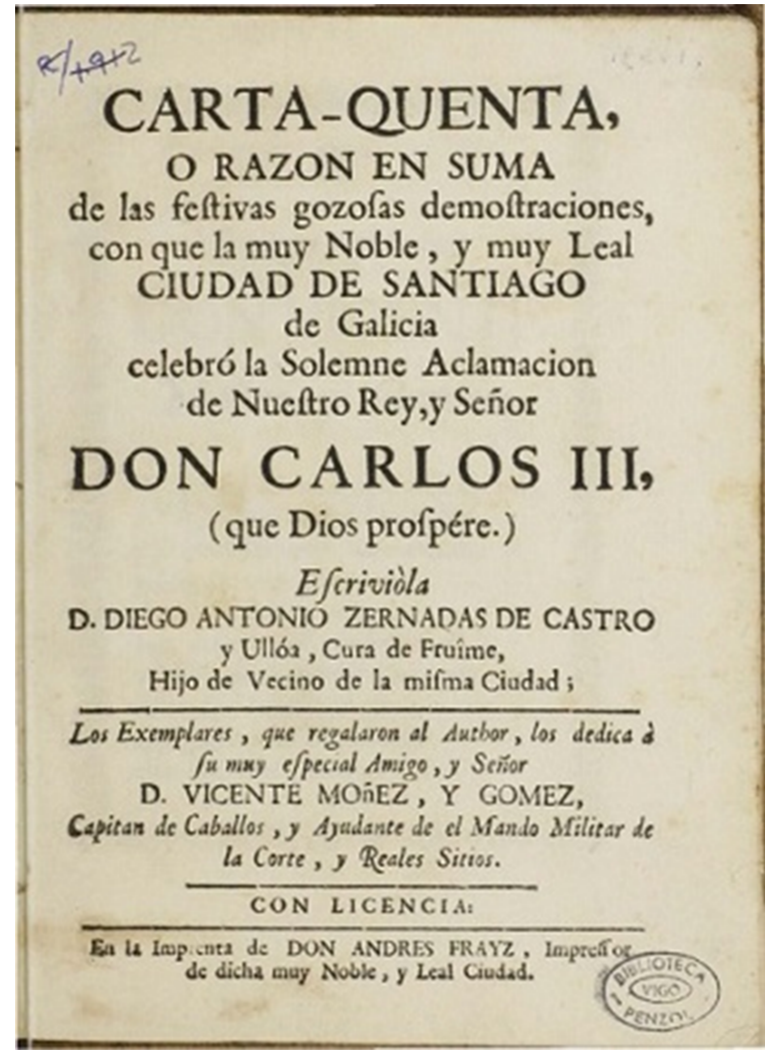


4

Voi, pues, à mi cuento.'Há de faber Vmd. (Amigo mio) que haviendo recibido la muy Noble, y muy Leal Ciudad de Santiago en I I. de Septiembre Carta de fu Mageftad la Señosa Reyna Governadora, en que le ordenaba, proclamarfe por Rey de las Efpañas à fu Hijo el Señor D. CARLOS TERCERO, (que Dios guarde) inmediatamente los Cavalleros Regidores quifieron dar à todo el Pueblo el alegron de tan feliz noticia, porque fabian muy bien con quanto gozo feria admitida, y celebrada de todos, nemine difcrepante, ò de placet: Acreditólo el hecho ; por qué

Quando fe iba pregonando, que à CARLOS por Rey tenian, por la fé, con que lo oían, todos fueron de aquel bando: tras el Bando, abandonando fus $C a$ aas, ví que abandadas las gentes aprefuradas iban clamando feftivas por todas bandas los Vivas, à Vanderas defplegadas.

La mifna noticia participó puntualmente la Ciudad por Cartas al Illmo. Señor Arzobifpo, fus Illmo. Cabildo, difcreto Provifor, Real

Hor-

Tenga Vmd. entendido, que de cftos $\mathrm{Ar}$ boles havo varios en otras Plazuelas, y por no andat fiempre por las ramas, galtando follages, y aumentando el folleto, demos por hecha la cuenta de los demás, falvo fi fe acravieffa alguna circunftancia agravante, que cs muy polsible.

Continuó la marcha hafta la Plazucla de la Plateria, ò encrucijada de la. Rúa de el Villar. Si huvieffe de pararme en defcribir efta Rúa, fería un juicio, conque no hay que meternos en dibujos locales. Batta decir ( fin perjuicio de las otras) que tiene la circunftancia de eftar titulada de punta à punta, ò de cabo à cabo: comprehende Cafás muy diftinguidas de Capitulares de la Santa Iglefia, y de Cavalleros muy Iluftes : con que vea Vmd. , fi eftaria noblemente iluftrada, y honrofamence lucida, ò ( on fraffe mas corufcante) efplendorofa. En la bo. ca de élla, y en la de los Cantores, (aludiendo à la Plateria, que eftá alli) (e oyeron cittas quazto palabritas.

$$
C A N T A D A \text {. }
$$

Reci QUIdonde Cinceles, y Buriles, tade A à cmulacion de Apeles, en dibujos, efcorzos, y perfiles ufurpan el primor à los pinceles, 

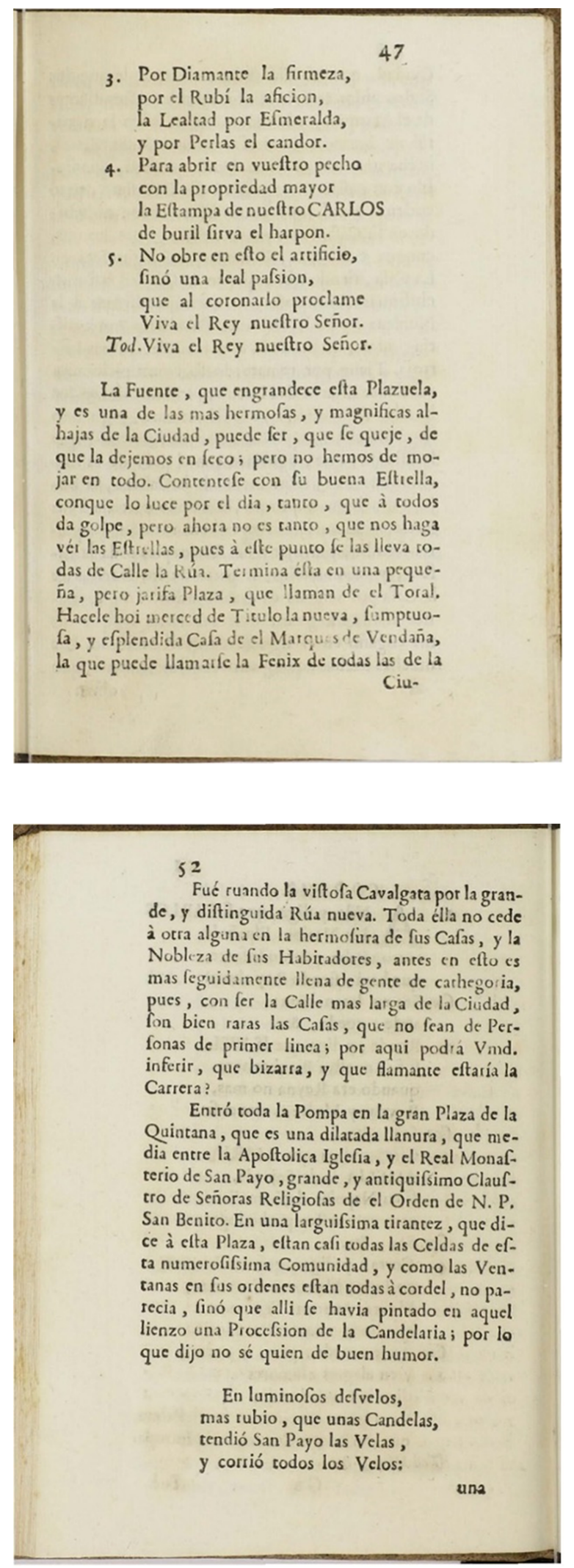


\section{Carta-quenta, o razón en suma de las festivas gozosas demostraciones, con que la muy Noble, y muy Leal Ciudad de Santiago de Galicia celebróla Solemne Aclamacion de Nuestro Rey, y Señor Don Carlos III, (que Dios prospére).}

\section{Escriviòla D. Diego Antonio Zernadas de Castro y Ullóa, Cura de Fruíme, hijo de vecino de la misma ciudad.}

\section{En la Imprenta de Don Andres Frayz, Impressor de dicha muy Noble, y Leal Ciudad [Santiago de Compostela, 1760]}

\section{[INTRODUCCIÓN Y JUSTIFICACIÓN, P. 1-3]}

[p. 2:] A la verdad yo no me atreviera à salir de el cascarón, si no viesse al Cortesano, y al Rustico, que Vm. me presenta desde essa Corte en este Correo. Pero viendo, que hasta los Rústicos Castellanos son bien oídos en este asunto, me pareció, que también podían hablar los Rusticos Gallegos, porque, aunque en punto de Rusticidad no les llevamos ventaja, en punto de lealtad, y fineza à nuestro Monarca no se la concedemos, mientras Galicia fuere lo que há sido, es, y será para sus Reyes: esto es, la mas obediente, la mas firme, la mas rendida, la mas amante Nacion (ò à lo menos la nunca excedida) de todas las demás de España, en la constante ley, con que venera à su legitimo Señor

\section{[ACONTECIMIENTOS PREVIOS, LUMINARIAS Y CAMPANAS NOCTURNAS, P. 4-18]}

[p. 4:] Há de saber Vmd. (amigo mio) que haviendo recibido la muy Noble, y muy Leal Ciudad de Santiago en 11 de Septiembre Carta de su Magestad la Señora Reyna Governadora, en que le ordenaba, proclamasse por Rey de las Españas à su Hijo el Señor D. Carlos Tercero, (que Dios guarde) inmediatamente los Cavalleros Regidores quisieron dar à todo el Pueblo el alegron de tan feliz noticia [...] por qué

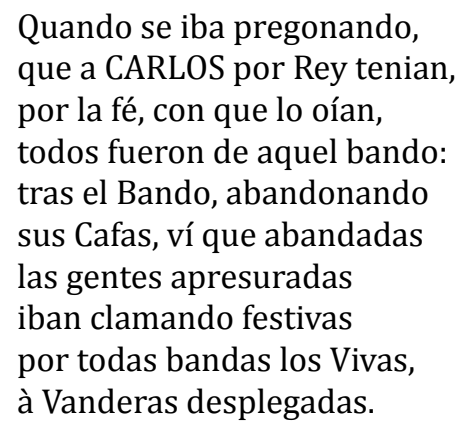


La misma noticia participó puntualmente la Ciudad por Cartas al Illmo. Señor Arzobispo, su Illmo. Cabildo, discreto Provisor, Real [p. 5:] Hospital, Colegio Mayor de Fonseca Universidad, al de San Clemente de Passantes, y mas Comunidades Eclesiasticas, y Regulares, á fin de que cada una de su parte contribuyesse a tanta celebridad con repique de Campanas, y Luminarias. [...]

Las Cartas fueron recibidas (yá se vé) con el mayor aprecio, y alborozo: todos se dieron por avisados, para darse por entendidos. Llegó la noche de el día siguiente [...]

[p. 6:] Acusome, pues, de que dige, que llegó la noche: no llegó, solo quiso llegar, y le llegó su hora, porque la mandaron sepultar solemnemente [...] Esto se le hará à Vmd. fácil de entender, si quiere hacerse cargo de que la Ciudad de Santiago para Fiestas de Fuego es un Rayo, y tiene particular Estrella, como lo acredita su Nombre Compostela. [...]

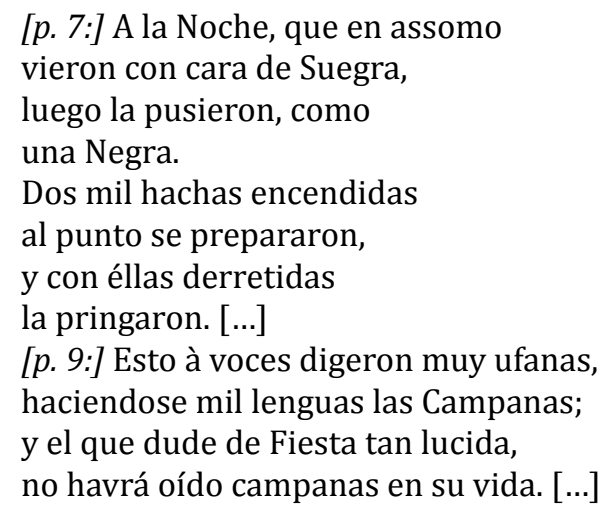

[p. 12:] Y no piense Vmd., que esto fué imaginacion de uno, ù otro: toditos los que nos hallamos en la Plaza de el Consistorio, salimos en el Juicio de que aquella no havia sido Noche, ni lo pareció [...] ya daba yo por sierto, que no havia mas que hablar de la llamada Noche, porque, como yá dixe, la consideraba en [p. 13:] el "otro" mundo; pero no fue assi, que solo se havia ido al otro barrio. Fue el caso, que viendo la pobre, que en la Plaza de el Consistorio la habían corrido, silvando, y agarrochando con tantas banderillas de fuego, quiso apelar de la sentencia de muerte à la Quintana de los Vivos [...] Pero llegó tarde, y aunque se adelantasse mucho mas, sería lo mismo, porque no era hora de Audiencia, à causa de que el Illmo. Señor D. Bartholome Rajoy, Meritissimo Arzobispo, y Señor de la Ciudad, y distinguidissimo honor de nuestra Nación, tenia dada providencia, de que no se le diesse entrada [...]. Vieron esto quantos tuvieron la curiosidad de observar los movimientos de la tal Noche, y seguirle los pasos, pues yendole à los alcances desde la Plaza de el Consistorio à la de Palacio, ya no le vieron mas el bulto [...]

[p. 14:] No descubrieron allí mas que la Magnificencia despendiendo esplendores, la Alegria rebosando placeres, y todo aquel sumptuoso Edificio, inflamado con el fuego de el corazón de su Illma., que ardía, por desahogar su complacencia en la Exaltacion de el Monarca, y en la fortuna de entrar a ser su Capellan Mayor. Todas las paredes de su gran Casa se colgaron de una costosa tela de lustre, sembrada á trechos de brillantes Piropos. Las ventanas parecían, no yá tragaluces, sino brotaluces, ò troneras de las que hai en las baterías, porque en todas, sin perder tiro, se gastaba la pólvora à carga cerrada, siendo esta la vez en que no fue ocioso gastar la pólvora en Salvas. Los balcones parecían aquellos en que dicen suele Phebo tomar el fresco de madrugada en las mañanas de Mayo. El terreno de aquella espaciosa Plaza, parecía un Jardin poblado de flores de mano, color de fuego, interveradas con otras de lentejuelas de alcamphor. Por un lado salía un hormiguero de Luciernagas, y por otros un tropel de fogosas Lagartixas [...] 


\section{[ACTOS DE LA FIESTA DE EXALTACIÓN, DESFILE Y MÁSCARA, P. 18-36]}

[p. 18:] No se hablaba despues de otro assunto mas que de celebrar la felicidad de la exaltacion de Nuestro Rey D. Carlos à su Trono, y assi luego supe, que los Cavalleros Regidores en pleno Consistorio havian determinado se dispusiesse otro festejo mas cumplido, señalando para esso los dias 13, 14, y 15 de este mes de Octubre [de 1759].

[...] Ordenaron, que en todos los tres dias señalados huviesse iluminación universal de calles, y que para el primero se ideasse una magnifica pompa, y solemne triumpho, en que con todo el possible aparato, y festiva ostentacion rodasse por toda la Ciudad [p. 19:] la alegria, el aplauso, y el alborozo, y resonasse en todos los angulos el glorioso nombre de Carlos Tercero. Para el desempeño assignaron cinco Capitulares. Al cuidado de el Conde de Priegue se fió la machina de fuego artificial, equipar los Reyes de Armas, y preparar el Real Estandarte, que se havia de tremolar el dia 14. A D. Juan Antonio Cisneros, D. Ramon Torrado, y D. Jofeph Bruno Becerra les encomendaron el adorno de los tres Teatros en que se havia de representar el Acto de la Aclamacion en las tres Plazas de el Palacio Arzobispal, la de Feijoo, y la del Consistorio. Al Liz[enciado] D. Juan Ramirez, Abogado de los Reales Consejos, y Regidor tambien, le diputaron para disponer la numerosa Cavalgata, y bizarra tropa, que havia de ir acompañando un Carro Triumphal sumptuosissimo. El pensamiento fué como de un Senado tan ilustre, como el Compostelano. Vmd., como está en Madrid, debe pensar, que solo Madrid es Corte.

Si Señor, solo Madrid es Corte de toda España, y aún (por la Grandeza de el Monarca) de toda Europa; pero Santiago tambien es Corte de este Gloriosissimo Reyno de Galicia, de el que es Cabeza. Bien sé que la Coruña alega su derecho à este Titulo, por ser residencia de [p. 20:] el Señor Capitan General, mas esso arguye, que es Corte de Galicia por Excelencia; pero Santiago, lo es por antonomasia, y porque aquí tiene su Solio el Generalissimo de las Armas Españolas. Por esso el Regidor Ramirez, Diputado para disponer el triumphal aparato (que aquí el Vulgo impropriamente llama Mascara) tomó la idea, y siguió en todo el aire de la Corte, trasladandola à esta Ciudad en vivo mapa, como lo dirá el dibujo, aunque sea de buril tosco. Ochenta fueron las Parejas de à caballo, con otras tantas de Volantes, que con hachas de cera blanca de à tres pavilos iban à sus lados, pegando fuego a las tinieblas por todas las calles, que fueron otras tantas vias lacteas, ò caminos de Santiago, con mas propriedad entonces, que nunca. [...]

Ponderar aquí la riqueza, la variedad, el buen gusto de los vestidos, jaezes, libreas, y trén de este festivo alarde, parecia muy del caso, pero...

[p. 21:] Decir aquí de las galas

lo precioso, es mucha ropa:

pues de los Caballos! esso

es cosa de mucha monta.

Presentaronse en la fiesta

con fogosidad tan pronta,

que me asseguran salieron

con el bocado en la boca.

Iban hechos unos brincos,

aunque siempre pie con bola,

muy iguales, muy derechos

sin corcobos, ni corcobas.

Todos corrian parejas, 
pero esso con mucha sorna, que las paridades corren, aunque à quatro pies no corran. Tan bien rizadas las clines llevaban, que unas pelonas eran con éllas las mas peynadas pelucas blondas. A contar las cintas, que ví pegadas con la cola, jamás se há visto Ciudad Señora de mas Colonias. Las herraduras... mas sús, algun Gongora no me oyga, que riña, porque no dixe, las aceradas Tiorbas.

[p. 22:] Llevaban de tal jaez los aderezos, que assombra, sin salir de las mantillas opulencia tan grandiosa. De Terciopelo, ò de Grana, que el oro, y la plata borda, iban con sus capotillos à lo majo las Pistólas. Por los pies la plata andaba, y élla estaba tan gozosa, que perdiéra los estrivos, si no fuese de essa forma. Huvo sus cascabeladas, pero no hai que hacer chacota, puesto que entonces aún essas se tuvieron por juiciosas.

Con tal modo, y compostura iban las Parejas todas, que igualaban en el Orden à una Procession de Monjas. Los Consejos: con que Acuerdo! que bien le estaban las Togas!

Pues los Guardias de Corps? que aire le daban las Vanderólas!

Los Essentos, que al estrivo van de la triunfal Carroza, con que gravedad atentos la miran, y no la tocan! [p. 23:] Pues Priegue, y Cisneros, que eran Capitanes de esta Tropa! aquél Marte, y éste Adonis, y ambos una cosa, y otra. Los Alabarderos: Guarda, que no iban de ceremonia; los Monumentos pudieran fiarse de su custodia. Las Virtudes, como entonces, nunca anduvieron de-botas, pues solo aquél dia hallaron 
de su zapato la horma ${ }^{1}$.

Con quatro Ninfas, que el Victor

cercaban de la Saxona,

por sus buenas bigoteras

los Barberos se acomodan.

Como Periquillo entre éllas

un Cupidillo enarbóla

el Victor, porque esta accion

de el Amor solo era propria.

De el Alma en las tres Potencias

los Pintores se transforman,

y en pintar como querer

sus phantasias se logran.

Con Petos, y Morriones

en parejas se eslabonan

los Herreros, y Canteros,

que huvo para todos obra.

[p. 24:] Sobre ir à diestro, y siniestro

varias protestas se toman,

y salió que los Canteros

una pica en Flandes pongan ${ }^{2}$.

Logran à punta de Lanza

salir con su Execuroria,

mas los Herreros la suya

hicieron à lima sorda.

Todos à dos Reyes de Armas

iban haciendo la escolta

en honor de los Escudos, que valian muchas doblas.

Los Sillateros delante

con vandas en vez de estolas,

de la gente la espesura

con hachas de viento cortan.

Humos todo, y luminarias

sus hachones, y sus chollas,

que à merced de Baco atizan

con el ayre con que soplan.

Las Cajas de la Milicia

Iban muy caballerosas,

porque en aquel lance tanto

como los Timbales montan.

El Pifano solfeaba

con musica tan bufona,

que bien se le conocía,

que estaba entonces de gorja.

[p. 25:] El Clarin iba muy hueco,

diciendo, que era à tal hora

con él un pobre Trompeta

el de la Fama ruydosa.

De toda esta Comitiva

con presencia Senatoria

el Diputado Ramirez

iba por Cabo de Ronda. 


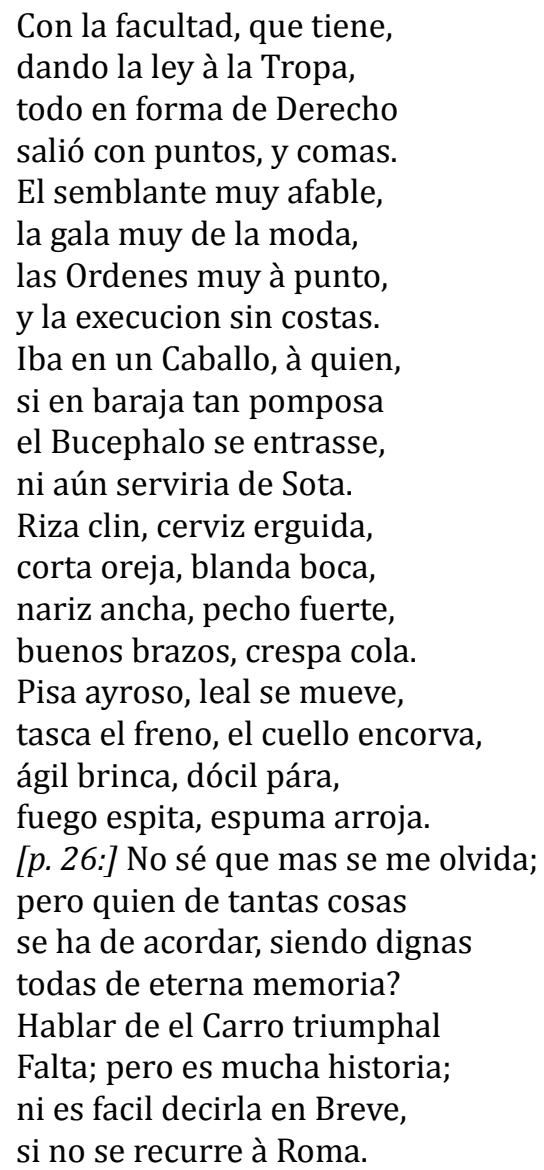

Y es assi, que si no se recurre à aquellos solemnissimos magnificos Triumphos de la antigua Roma, en que los Cesares, ò Cónsules vencedores eran conducidos en carros de oro, adornados de varios tropheos, tirados de selectissimos caballos, seguidos de la Nobleza, y la Plebe, y aclamados à una voz de la multitud innumerable, no se puede dar un diseño de lo que há sido el Triumpho, con que la Ciudad de Santiago (por no pocos titulos tan semejante à la de Roma) celebró este dia faustissimo de la Exaltacion de Nuestro Carlos III. Dixe un diseño, porque pintura cabal de este festivo aparato, ni aún los de Roma antigua podian serlo, à lo menos por una circunstancia bien notable; y es, que en los Carros triumphales Romanos no iba mas que el Cesar, Consul, ò Capitan vencedor, ò, à lo [p. 27:] mas, sus hijos, pero en el nuestro iba toda la Real Familia de Nuestro Soberano, yá que no en sus Personas, en sus imagenes. Nuestro Amabilissimo Carlos se dexaba venerar de todos en un primoroso Retrato, que en aquellos dias se hizo de nuevo, colocado en el lugar mas sublime. A su lado iba representada su dignissima Consorte nuestra Reyna, y Señora Maria Amelia. En lugar correspondiente la Augustissima Reyna Madre, Governadora; sus dos Serenissimas Hijas la Reyna de Portugal, y la Duquesa de Saboya, y sus dos felicissimos Hijos el Señor Duque de Parma, y el Señor Infante D. Luis: todos en Estatuas vivas, que, si en el vestido, y Reales insignias figuraban sus Originales, en sus corazones los llevaban mas noble, y mas vivamente impressos, ò estampados. [...]

El modo con que iban colocados, tenia [p. 28:] su émphasis igualmente curioso, que fino. El respaldo de el assiento de la Señora Reyna Madre era un frondoso Laurel, de que salian otras tantas ramas, como son sus Augustos Hijos, y formandose de éllas unos arcos, les servían de Coronas. El 
Emblema no podia ser mas propio, ni mas significativo, con que basta para explicarlo la Letra, que en una Vanda, ò Liston, que se entretegia con el Laurel, decia: A solis ortu usque ad occasum.

En la proa de el Carro iban dos Leones enarmonados, que en sus garras sostenian dos globos unidos, de cuyo medio salia un Victor, iluminado à ambas faces, con el nombre de Nuestro amantissimo Monarca, que solo en caracteres de luz, y de fuego podia estar dignamente cifrado.

En estancia inferior al Solio se dispuso una Orchestra espaciosa para los Musicos de la Santa Cathedral, assi Voces, como Instrumentos, que à pausas alternaban yá Sonatas, yá Letrillas, de que adelante daré traslado.

Tiraban de esta vistosa Regia Maquina (toda iluminada de multitud de hachas, y variedad de Arañas muy preciosas) quatro yuntas de bien robustos, y proporcionados brutos, que, aunque en la realidad eran de una especie misma, en [p. 29:] la representacion la tenian muy diversa, porque el noble discurso de el Cavallero Diputado tuvo arte para disponer una ingeniosa metamorphosis, con que hiciessen figura, que picasse en misterio, y en simbolo bien oportuno declarassen su elevado pensamiento. Disfrazólos, pues, con mascaras de Hombre, Leon, Buey, y Aguila: idea de los Cielos, para hacer memorable una Carroza, que havia de ser predicada, y ponderada en toda la rueda de el Orbe. [...] Solo diré, que nuestro Carro triumphal (que el vulgo llamaba triumphante con bastante razon) no há menester mas pruebas de su magnificencia, sumptuosidad, y primoroso adorno, que haverle tocado su hechura al Gremio de la Plateria, que disputó esta preeminencia à los Mercaderes de Vino, alegando possesion de no menos tiempo, que el que há se Beatificó el Santo Rey Fernando. Vea Vmd. si en este Carro rodaria la Plata, y si no iría todo de oro, y azul. [...]

[p. 33:] En esto observé, que, dispuesta yá la Tropa, para dar principio à su marcha, se pedía silencio, para oîr las ordenes [...]

[p. 36:] Entendió la Musica un Organo de fuego artificial, que estaba esperando su vez, y soltando todos los registros, corrió todo el teclado con un manejo tan pronto, y sonó tan de lleno, que cubrió las voces de todo el populosissimo concurso, de suerte, que no se oían unos à otros [...]

\section{[PROCESIÓN FESTIVA POR LA CIUDAD, P. 36-60]}

Empezó à moverse toda la numerosa Cavalgata en el orden poco mas, ò menos, que vá romanceado, y en llegando à la Plaza de la Acevacheria, huvo una gran competencia de lucimientos; porque el Palacio del Ilustrissimo Señor Arzobispo, y la magnifica, dilatada, y sumptuosissima fachada del Monasterio de S. Martin, (al [p. 37:] fin Casa Real) estaban tan de apuesta rebosando luces, que se las empataban à las de la numerossisima Comparsa; y sobre quales brillaban menos, ò mas, hubiera su mas, y su menos, si todas no ardiessen en un mismo fuego, que era el amor à nuestro Soberano. Como todo estaba tan claro, huvo alguno, que reparó en que la Fuente, que hay en aquella Plaza, hacia agua de su titulo de S. Juan, ostentando su Señoria su clarissima progenie, y dando pruebas de su limpieza, y liberalidad, con que brindaba à todos con un copioso refresco en honor de tanta funcion; pero todos lo entendieron al contrario, pues les pareció les decia agua vá, segun se retiraban de que les aguasse el contento. Lo que no tiene duda es, que élla no hacia sinó correr à todo trote por seguir la corriente de la alegre Comitiva; y de hecho no le partió pie hasta cerca de el Hospital, que alli se extravió; quedando después, que la perdió de vista, llorando de pena, de que se le desapareciesse tan presto aquella vision gloriosa.

Otro, reparando en la Estatua de $\mathrm{S}$. Martin à caballo, que corona el elevadissimo frontispicio de aquel Real Monasterio, se austó, por haversele figurado, que el Cavallo, embidioso de el lucimiento 
de tantos, como iban en la Carre-[p. 38:] ra, queria de un brinco saltar à tierra, para incorporarse en la tropa, y no le passó el sobresalto, hasta que reconoció, que el Santo le tiraba de la rienda, y le hacia estar à la capa, porque, como Cavallero, y Militar, hecho cargo de que estando de guardia, ò centinela, no debia largar el puesto, aunque passasse el Rey, se estuvo allí quietecito, como un Santo. El cuento fue, que el Cuervo, que está al pie de el corpulento Simulacro de el Gran Patriarca S. Benito, que honra la espaciosa Portada, pasmado de tan inaudita algazára, iba à quedarse con la boca abierta, y por poco no se le cayó el panecillo, en que se vé el milagro de estar la piedra convertida en pan; pero con todo se amañó, de suerte, que sin soltarlo de el pico, como esto era en la vispera de la solemne, y formal Aclamacion de el Rey, estuvo (según concibieron algunos contemplativos) graznando alegremente su Crás, Crás, como anunciando el colmado gozo de el siguiente día. Entre tanto se fue acercando el Carro à las puertas de el Palacio Arzobispal, en donde la Música cantó el siguiente Invitatorio [...]

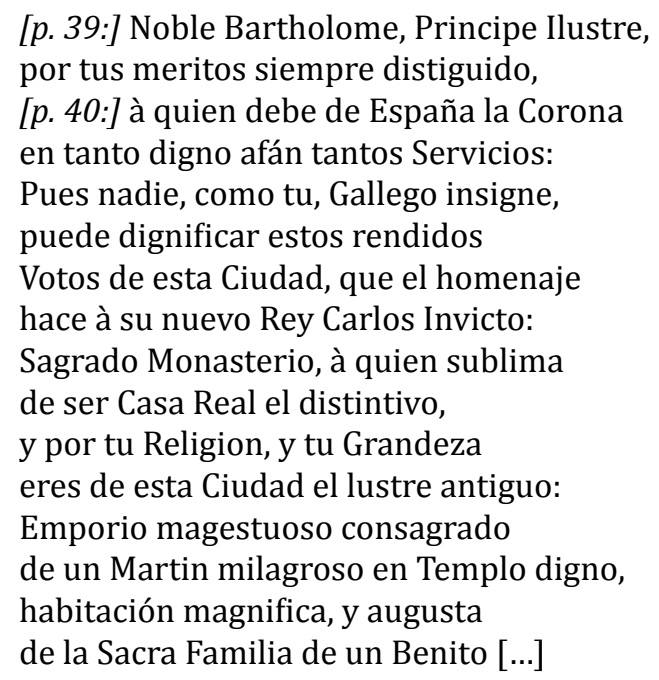

[p. 41:] Prosiguió la bizarra Quadrilla su Carrera por debajo de el Arco de Palacio, que en aquélla ocasion tuvo vanidades de Arco triumphal, y entrando en la espaciosissima Plaza del Hospital, hizo alto frente la Puerta principal de la Apostólica Basilica (no tema Vmd. que se la pinte aquí, porque es mucha obra) en donde la Música cantó la siguiente Oración [...]

[p. 42:] Unico Tutelar de las Españas, à quien nuestros Monarcas reverentes, alentados de Vos en las Campañas, deben quanto Laurel ciñe sus frentes, desde hoi dia en que Carlos sus azañas de vuestra Proteccion pone pendientes, haced siempre feliz su Real Persona, pues por vuestra conoce la Corona. [...] Si en Compostela la Noble, y Leal hoi ciñe Carlos su Regio Laurel, lo hace en lugar de Jacob Celestial, porque se sepa, que un Rey, como es El, debe a Santiago el Imperio Español. [...] 
$\mathrm{Al}$ ayre de estas afectuosas respiraciones empezaron a moverse las hojas de un Arbol, que el [p. 43:] Cavallero Diputado havia dispuesto se plantasse allí, para que encendido al soplo de las ardientes, y amantes Aclamaciones, respondiesse à éllas con otras iguales. Era un frondosissimo Laurel, de quien se dice, que (en la antigua observacion) quando en el fuego daba ruidosos estallidos, era fausto anuncio de felicidades, como al contrario, quando ardia mudo. Pero éste, sea Dios bendito, habló por los codos, y por todas sus coiunturas en lenguas de fuego, hasta las ultimas boqueadas $[\ldots]$

[p. 45:] Tenga Vmd. entendido, que de estos Arboles huvo varios en otras Plazuelas, y por no andar siempre por las ramas, gastando follages, y aumentando el folleto, demos por hecha la cuenta de los demás, salvo si se atraviessa alguna circunstancia agravante, que es muy possible.

Continuó la marcha hasta la Plazuela de la Plateria, ò encrucijada de la Rúa de el Villar.

Si huviesse de pararme en describir esta Rúa, sería un juicio, conque no hay que meternos en dibujos locales. Basta decir (sin perjuicio de las otras) que tiene la circunstancia de estar titulada de punta à punta, ò de cabo à cabo: comprehende Casas muy distinguidas de Capitulares de la Santa Iglesia, y de Cavalleros muy Ilustres: con que vea Vmd. si estaría noblemente ilustrada, y honrosamente lucida, ò (en frasse mas coruscante) esplendorosa. En la boca de élla, y en la de los Cantores, (aludiendo à la Plateria, que está alli) se oyeron estas quatro palabritas [...]

Aqui donde Cinceles, y Buriles,
à emulacion de Apeles,
en dibujos, escorzos, y perfiles
usurpan el primor à los pinceles,
[p. $46:]$ para que el fino azero
el Nombre grave con mayor decóro
de nuestro Amado Rey Carlos Tercero
en Laminas de plata, en Tablas de oro,
suspenda el curso la festiva Pompa,
y publique la fama con su Trompa
el tributo, que à Carlos este dia
debe rendirle fiel la Plateria. [...]

[p. 47:] La Fuente, que engrandece esta Plazuela, y es una de las mas hermosas, y magnificas alhajas de la Ciudad, puede ser, que se queje, de que la dejemos en seco; pero no hemos de mojar en todo. Contentese con su buena Estrella, con que lo luce por el dia, tanto, que à todos da golpe, pero ahora no es tanto, que nos haga ver las Estrellas, pues à este punto se las lleva todas de Calle la Rúa. Termina ésta en una pequeña, pero jarifa Plaza, que llaman de el Toral. Hacele hoi merced de Titulo la nueva, sumptuosa, y esplendida Casa de el Marques de Vendaña, la que puede llamarse la Fenix de todas las de la [p. 48:] Ciudad, que renació de las cenizas de la que dos Siglos antes tenían alli los Nobles Ascendientes de el Marques, y havrá quarenta años la derritió un incendio, para salir ahora de el Crisól, hecha una taza de Plata. Vmd. pensará, que hablo con passion: tengosela à este Caballero, pero entienda Vmd., que jamás hé comido, ni bebido en su Casa, aunque le debo algunas honras, con que vea Vmd., si me moverá algun interés.

La Casa, siendo assi, que en la Ciudad hai muchissimas primorosas, y correspondientes à la Nobleza, y poder de otros Cavalleros muy distinguidos, es sin duda la mas linda, y mas lustrosa. Tiene por remate de su frontispicio una excelente Estatua de Hercules, sosteniendo en los hombros el globo, que le fió Atlante, y quando llegó alli el triumphal aparato, me pareció, que la Estatua, que, agoviada con el peso de la machina rotunda, tiene inclinada la Cabeza, la bajaba mucho mas, como, 
haciendo cortesia à los Retratos de nuestros Reyes, en ademán de querer sacudir, y arrojar à sus Reales pies toda la Esfera, y reconocerlos de parte de los Dueños de la Casa por Señores de dos Mundos. Yo à lo menos assi lo imaginé, y estoy cierto de que no me engaño en el significado de el Simbolo. Las muchas hachas, que guarnecían los balcones, que [p. 49:] ciñen el dilatado lienzo de la fachada, y su costado, multiplicaban sus brillantezes con la reververacion de los christales de puertas, ventanas, y postigos, de suerte, que centelleaba tanto, que pudo ahora gloriarse de que el incendio trágico, que havia padecido la antigua, se havia desquitado con el festivo lucimiento de ahora, pero lo que mas bien parecia entre tanto fuego era la Salamandra. Hace machado con esta Casa otra de su misma simetria, en que está la Administración de las Rentas Provinciales, cuyo Dueño ostentó la fidelidad, el amor, y el gozo en la Exaltacion de su Amo el Rey con tan copiosos esplendores, quantos caben en el seno grande, y capacissimo de un Seron.

Detuveme aquí, y no lo hice, ni haré en otras nobilissimas estancias, nada menos dignas de mi atencion, porque no debo hacer mas Estaciones, que las que hizo el Passo, y lo demás seria marear el Calvario. Yo sigo la Real Carroza, y no puedo hacer mas paradas, que ella [...]

[p. 52:] Fue ruando la vistosa Cavalgata por la grande, y distinguida Rúa nueva. Toda élla no cede à otra alguna en la hermosura de sus Casas, y la Nobleza de sus Habitadores, antes en esto es mas seguidamente llena de gente de cathegoria, pues, con ser la Calle mas larga de la Ciudad, son bien raras las Casas, que no sean de Personas de primer linea; por aqui podrá Vmd. inferir, que bizarra, y que flamante estaría la Carrera?

Entró toda la Pompa en la gran Plaza de la Quintana, que es una dilatada llanura, que media entre la Apostolica Iglesia, y el Real Monasterio de San Payo, grande, y antiquissimo Claustro de Señoras Religiosas de el Orden de N. P. San Benito. En una larguissima tirantez, que dice à esta Plaza, estan casi todas las Celdas de esta numerosissima Comunidad, y como las Ventanas en sus ordenes estan todas à cordel, no parecía, sinó que alli se havia pintado en aquel lienzo una Procession de la Candelaria; [...]

[p. 53:] Circuló por toda la Plaza el festivo alarde con grave, y acorde pausa, como que passaba la revista à presencia de el Generalissimo de las Armas de España su Patron Santiago, cuya magnifica Estatua à caballo, colocada sobre la eminente coronacion de la Puerta de el Relox, está infundiendo veneracion, y respeto. Fué tan divertido el Passeo, que el Relox, que tiene en su portentosa Torre balcon pagado para semejantes funciones, todavia por lo extrahordinario de esta tuvo la galanteria de dar sus dos quartos (otros dicen que tres) por verla; y no piense Vmd. que fué poco, porque el tiempo es preciosissimo, y fué de este metal la moneda. Todavía daría mas, pero no le havia llegado su hora, y esso lo toma él conforme caen las pesas: fuera de que era por demás, porque todo aquello iba gracioso. La Puerta de los Perdones estuvo en un tris de salir de sus quicios, pensando por el inmenso gentío, que era vispera de año Santo, [p. 54:] hasta que se hizo cargo de que aquello era Júbilo, y no Jubileo, aunque solo por Jubileos se logra un júbilo plenissimo, como este. Otro Arbol, como el que se dijo, echó aqui su planta, como el mas guapo.

Tomó la ruta el festin à la Plazuela de Feyjó, por otro nombre la de la Hierva: porque en élla se vende el forrage para todo el ganado de el Lugar. Es pequeña, pero agraciada por los bellos Edificios, que la circundan. Entre estos está la Casa de el Regidor Decano, à quien tocaba en el siguiente dia levantar el Real Estandarte, llamado D. Joseph Antonio Somoza, y Ossorio, que es un Caballero de una noble calidad, y condición, venerable, apacible, y pundonoroso: con que yá podrá Vmd. conjeturar, que tales estarían sus Balcones, especialmente, quando los condecoraba su Muger, que es una Matrona de alta jerarquía, muy afable, de una grande humanidad, y tambien Decana de las Señoras de el Lugar. Aqui se cantó (atendiendo à las circunstancias de el sitio) la siguiente 
Letrilla en el dialecto Gallego, porque como era natural, era el proprio. Dame al alma, que à Vmd., como es de la Corte, le há de disonar este idioma, y aun decir (en el sentido que allá le dan) que es una Gallegada. Pero Vmd. no dirá bien, si dice [p. 55:] esso, porque los Reyes, que son en la tierra los mas vivos retratos de Dios, deben ser, en su proporción, alabados, como el todo Poderoso, y à éste le magnifican no solo todos los Pueblos, Tribus, y Naciones, sinó tambien todas las Lenguas, y no era razon, que los Gallegos no la tuviesen para ensalzar à su Señor, y que los Castellanos no los dejen hablar con la lengua, que Dios les dió. Vmd. haga de caso, que ésta fue noche de Villancicos, y en estos, yá veria Vmd. entrar el Italiano, el Portugués, y Totilimundi.

Facil me seria traducirsela à Vmd. en Castellano, pero, sobre estar bastante inteligible, perdería su nativa gracia, la que por acá le hallaron los que lo entienden. [...]

[p. 59:] Crea Vmd., que esta Foliadilla le gustó à la turba, porque à cada uno le sabe lo que sabe.

Corrió la Fiesta su rumbo à terminar en las Casas de el Consistorio, de donde havia salido; sin que en el trecho, que faltaba, se notasse cosa especial. Solo un atisbador de pensamientos, parece le percibió à la Madama de Cisneros, que quando este Cavallero iba passando por su puerta en ayre de Capitan de Guardias Españolas, al hacerle (como era natural) un amoroso acatamiento, le havia correspondido, ò bien fuese vocal, ò mentalmente, cantándole aquella vulgar, pero chusca Siguidilla [...] [p. 60:] Puedesele passar por el amor de Esposa; pero lo cierto es, que assi Cisneros, como su Compañero el Conde de Priegue, y todos los demás iban alli en cuerpo, y alma, sirviendo al culto, y à la veneracion de nuestros Amantissimos Reyes, y que no se les acordaba entonces Muger, ni niño muerto. Luego que llegaron à la puerta de el Consistorio se profirió con aliento afectuoso el siguiente Recitado [...]

\section{[ACTOS DE LA FORMAL ACLAMACIÓN, P. 61-76]}

[p. 61:] Con esto se dió fin à esta función, y siendo estas las Visperas, dicho se está lo que seria el dia de la formal Aclamacion, que fué el siguiente. Como el Ceremonial de esta es, en su proporcion, el mismo de essa Corte, tengo por superfluo especificarlo aquí. Suponese el aparato de Clarin, Cajas, Pifanos, Maceros, Ministros, Secretarios, Reyes de Armas, todos de gala à la perfeccion (aun aquellos que por costumbre debian ir, y fueron de Golilla) en Caballos ricamente enjaezados, con sus Volantes al pie curiosamente vestidos. Presidian las dos filas de Cavalleros Regidores los dos Alcaldes D. Joaquin de Lossada, y D. Bernardo de Millara, también Regidores, y en medio de éllos, como Decano, llevaba el Real Estandarte el yá dicho D. Joseph Antonio Somoza, que lo hacia con aquel acierto, que enseña la experiencia, pues no era la primera vez, que lo ejecutaba, y parece nació con estrella de llevar la Voz en la Proclamacion de nuestros Reyes. [...]

[p. 62:] El primer Teatro de los tres, en que se havia de aclamar al Rey, estaba à la puerta de el Palacio de el Ilustrissimo Señor Arzobispo, que bajó à él, y puesto en pie, à la izquierda de el Cavallero Decano, fué, como el primero en la Dignidad, el que dió el punto, para que toda esta gran Ciudad (de la que su Ilustrissima es Señor por merced de los Reyes) entonasse afectiva, y efectivamente la respuesta à la intimacion, que hizo el Decano à todos, de que era nuestro Rey el Señor D. Carlos III. Derramó Somoza sobre el Pueblo una copiosa lluvia de monedas de plata, por señas, que à mi no me tocó siquiera una, porque tengo una fortuna tan grande, como el Arca de Noé, que me tiene tan cerrado à semejantes diluvios, que aunque se [p. 63:] anegue el mundo en caudalosas corrientes, me quedo siempre en seco. [...] 
[p. 64:] Esta bizarra profusion, y el triplicado saludo de el Regimiento de Milicias (que para este efecto anticipó su Assamblea) se repitió en los dos Puestos restantes, con lo que se concluyó este solemne Acto; pero no el festejo de repique universal de Campanas, Luminarias, y Fuegos, que se continuó con igual empeño, y gusto al de las noches antecedentes, en la de este dia, y el siguiente, durando hasta cerca de las diez. Solo huvo la diferencia de que la Fuente de la Plaza de las Casas Consistoriales, estuvo adornada con varios arcos, y coronacion de fuegos, que remataba con un Victor de el Rey, Nuestro Señor, iluminado, que duró assi desde poco despues de anochecer hasta casi las diez. Pero porque vea Vmd., que las obras, invenciones, y artificios, por primorosos que sean, una vez que se expongan al publico, estan sugetas à la censura de todos, y ni un Apeles pudo librar sus lienzos de que se los tiznasse el cerote de un Zapatero [...]

[p. 69:] [...] como pasaba yà de [p. 70:] las diez, se me roían las tripas, por ir à la Comedia, ò la Scena. Ibame retirando à Casa mas que de passo, pero, todavia quiso mi fortuna, que al passar por la Quintana de los muertos, se me atravesasse en el camino una chuscada, que me detuvo, y fué la de un Xacaro, al parecer Cadete de Milicias, que, rasgueando con destreza una Guitarrilla, sentado debajo de los balcones (quizá por dar que oir à las Rejas) cantaba con lindo despejo el siguiente Cortidillo [...]

\section{[DESPEDIDA, P. 76-77]}

[p. 77:] Su mas fiel apassionado, que S. M. B.

Diego Antonio Cernadas y Castro

Notas

$1 \quad$ Al margen: Tocò al Gremio de los Zapateros representar las 7 Virtudes.

2 Al margen: Por concordarlos, se convinieron en que los Canteros, que son de la Cofradia de Santo Thomas, à quien pintan con una Lanza en la mano, la llevasen por divisa. 